and harder as they take on more tasks and because the leaders of the GMC are anxious to head off any proposal to scrap the council and introduce a new organisation dominated by lay people.

At the moment there are 11 lay members-appointed by the Privy Council on the advice of the health departments. Trying to spot the reasoning behind the appointments is a favourite game, but by custom rather than law two members in recent years have been members of parliament. One radical possibility would be to make lay members the majority, but the council is not ready for this. The council is thus likely to go for a much more modest increase-to something like 20 . The question that immediately arises is whether these people should be appointed in the traditional way or whether they should be elected. If the aim is increased accountability it would obviously make sense to have the lay members elected rather than plucked from Hampstead dinner tables or from among Bradford butchers. But how? Tacking a poll on to public elections seems impractical, and electing members from unelected bodies like the Association of Community Health Councils or the Patients Association might decrease rather than increase representativeness. But elected lay members would surely be better than appointed ones.

Once the council has increased its lay members it must think whom to discard if it is to shrink rather than expand. The choice lies among the 21 members from the universities, the 14 from the other bodies producing registrable qualifications (the royal colleges and faculties and the Society of Apothecaries), the two chief medical officers, and the 54 elected members who are needed to make sure that they have a comfortable enough majority not to need a byelection every time one of the members resigns or dies.

It's a matter of arithmetic, and the officers of the council and its members have been occupying themselves with it for some time. The rules of the game are that there must be an overall majority of doctors who have been elected (the idea that history might be rolled back and the elected members reduced to a minority was quickly killed), an increase in lay members, somebody from the government, somebody representing those granting registrable qualifications, and as small a council as possible. Another complication is that there should surely be at least somebody representing the consumers of undergraduate medical education-medical students. Most university authorities now have students represented, and the BMA's council includes students. At least two students should be elected: they would need mutual support.

One possible formula would be 20 lay members, one chief medical officer, four representatives from the universities and two from the other bodies producing registrable qualifications, two medical students, and 32 elected doctors-a total of 61 . Better still might be to reduce the lay membership to eight and shrink the overall council even further, meaning that lay membership would increase proportionately. This could lead to a council of 30 , saving doctors money (at a time when the retention fee looks set to explode) and increasing the effectiveness of the council.

RICHARD SMITH Editor

$B M \mathcal{F}$

\title{
Bone gain and loss in premenopausal women
}

\section{Physical activity, calcium nutrition, and sex hormone status are important}

Low bone mass is an important determinant of age related fractures, and public health strategies to reduce the burden of these fractures currently aim at maximising the bone mass of elderly people. Bone mass in later life depends on both the peak attained during growth and the subsequent rate of loss. Although the risk factors for bone loss have been extensively studied, ${ }^{1}$ the determinants of peak bone mass have only recently received the attention they deserve. We highlight three developments in our understanding of peak bone mass: the recognition that environmental factors have a role in its attainment; evidence that certain interventions during youth are capable of increasing bone gain during growth; and better information about the hormonal influences on skeletal status from studies of pathological conditions affecting premenopausal women.

Twin and family studies provide clear evidence that there is a substantial genetic contribution to peak bone mass. The size of this contribution is difficult to quantify, however, as estimates of heritability tend to underestimate the influence of environmental factors. The most recent data suggest that as much as half of the variation in peak adult bone mass among women is non-genetic. ${ }^{2}$

If environmental factors determine peak bone mass, what are they and can they be beneficially manipulated? Recent studies implicate physical activity, calcium nutrition, and sex hormone status as the three most important determinants. Cross sectional studies have shown associations between indices of physical activity and bone mass, especially in the proximal femur, among children and young adults. In a study of 6-14 year old children those who spent more than two hours a day in weightbearing activities had around $10 \%$ greater wrist, spine, and hip bone mineral density than those who spent less than an hour each day in such activities. ${ }^{3}$ Data from a British national birth cohort study suggest that patterns of activity may track from school years into adult life, so that the benefit obtained from maintaining a high level of physical activity in childhood might be preserved in later decades. ${ }^{4}$ Finally, the only randomised controlled trial of exercise in premenopausal women showed that exercise significantly increased the mineral density of the young female skeleton. ${ }^{5}$

The relation between calcium nutrition and peak bone mass is less consistent. Observational studies have reported an association between the intake of dietary calcium in childhood and bone mass in adulthood, but studies in growing children have failed to replicate this finding. Nevertheless, a three year, double blind, placebo controlled trial of calcium supplementation in 22 twin pairs aged less than 14 years recently showed significantly greater bone gain in the forearms and lumbar spines of prepubertal twins who received a daily supplement of $1 \mathrm{~g}$ calcium compared with those receiving placebo. ${ }^{6}$

The greatest absolute rate of mineral accretion in the skeleton occurs during puberty. Numerous metabolic and hormonal changes occur at this time, including increases in the production of growth hormone, gonadotrophins, and sex steroids. Precisely how they influence skeletal development, however, remains elusive. Clues to this hormonal regulation have emerged from studies in older, though still premeno- 
pausal, women with disordered endocrine function. The disease models which have been most extensively investigated are those of athletic amenorrhoea and anorexia nervosa. Athletic or exercise induced amenorrhoea is a type of hypogonadotrophic hypogonadism that characteristically affects women engaged in intensive long distance running. In this setting decreases in serum oestradiol and luteal phase progesterone concentrations seem associated with an accelerated loss of trabecular bone, despite the increased mechanical loading of the skeleton. ${ }^{7}$ Milder disturbances of ovulation or cycle length in female athletes are also associated with decreased spinal bone mineral density. ${ }^{8}$ Furthermore, amenorrhoea from other causes-for example, hyperprolactinaemia-has been shown to predispose to progressive spinal osteopenia. ${ }^{9}$ If untreated, hyperprolactinaemic women with amenorrhoea have vertebral bone mass values almost one fifth less than those expected for their age. Although bone loss in the disorder is related to menstrual status, one study has reported that changes in spinal bone mass among hyperprolactinaemic women do not correlate with oestrogen status, suggesting that prolactin may have a direct effect on bone cells or calcium absorption. ${ }^{10}$ The extent to which restoration of menstrual cycles in amenorrhoeic women restores bone mass to normal is uncertain.

Anorexia nervosa provides an even more graphic example of disturbed bone metabolism in premenopausal women. Oestrogen deficiency, malnutrition, and glucocorticoid excess are associated with anorexia nervosa, and all of these may contribute to rapid cortical and trabecular bone loss and fracture. In one longitudinal study of the disorder weight gain, resumption of menstrual function, calcium supplementation, and exercise were not associated with appreciable restoration of skeletal mass over two years, ${ }^{11}$ although a cross sectional study has suggested that bone mass might return to normal after five to 10 years.
These studies suggest that oestrogen status, exercise, and calcium nutrition are the most important, modifiable contributors to peak bone mass. The findings present a challenge to both clinician and epidemiologist. For the clinician clear therapeutic guidelines for the restoration of bone mass in certain readily identifiable disease states are urgently required. For the epidemiologist the design and evaluation of population wide strategies to improve skeletal accretion in childhood and adolescence become a priority.

CYRUS COOPER

MRC Environmental Epidemiology Unit, MRC clinical scientist

University of Southampton,

Southampton General Hospital,

Southampton SO9 $4 \mathrm{XY}$

RICHARD EASTELL Senior lecturer

Clinical Sciences Centre,

Northern General Hospital,

Sheffield S5 7AU

1 Eastell R, Riggs BL. Endocrinology and aging: calcium homeostasis and osteoporosis. Endocrinol Metab Clin Norh Am 1987;16:829-42.

2 Krall EA, Dawson-Hughes B. Heritable and lifestyle determinants of bone mineral density. $\mathcal{F}$ Bone Miner Res 1993;8:1-10.

3 Slemenda CW, Miller JZ, Hui SL, Reister TK, Johnston CC. Role of physical activity in the development of skeletal mass in children. 7 Bone Miner Res 1991;6: 1227-33.

4 Kuh DL, Cooper C. Physical activity at 36 years: patterns and predictors in a longitudinal study. f Epidemiol Community Health 1992;46:114-9.

5 Snow-Harter C, Bouxsein ML, Lewis BT, Carter D, Marcus R. Effects of resistance and endurance exercise on bone mineral status of young women: a randomised exercise intervention trial. $₹$ Bone Miner Res 1992;7:761-9.

6 Johnston CC, Miller JZ, Slemenda CW, Reister TK, Hui S, Christian JC, et al. Calcium supplementation and increases in bone mineral density in children. N Engl f Med 1992;327:82-7. Drinkwater BL, Bruemner B, Chesnut $\mathrm{CH}$. Menstrual history as a determinant of current bone density in young athletes. $¥ A M A$ 1990;263:545-8.

Prior JC, Vigua YM, Schechter MT, Burgess AE. Spinal bone loss and ovulatory disturbances. NEngl f Med 1990;323:1221-7.

9 Wardlaw SL, Bilezikian JP. Hyperprolactinaemia and osteopenia. 7 Clin Endocrinol Metab 1992;75:690-1.

10 Schlechte J, Walkner L, Kathol M. A longitudinal analysis of premenopausal bone loss in healthy women and women with hyperprolactinaemia. J Clin Endocrinol Metab 1992;75:698-703.

11 Rigoti NA, Neer RM, Skates SJ, Herzog DB, Nussbaum SR. The clinical course of osteoporosis in anorexia nervosa: a longitudinal study of cortical bone mass. $\mathscr{f} A M A$ 1991;265:1133-8.

\title{
Rural health and health care
}

\author{
Unjustifiably neglected in Britain
}

Concern over Britain's health service has focused almost exclusively on the problems of urban areas, ${ }^{1}$ reflecting the general urban dominance in the cultural, economic, and political spheres of contemporary British society. ${ }^{2}$ This urban bias results in the belief that rural areas escape the social problems of cities, whose populations are less healthy. Other developed countries have problems associated with rurality, but in Britain the NHS is assumed to prevent them. ${ }^{1}$ Such assumptions merit further attention-if found to be incorrect then increasing the priority given to health and health care in Britain's rural population may be warranted.

Although urban districts have a higher mortality than rural ones, ${ }^{34}$ subtle variations may exist-for example, mortality in some rural districts in the north is higher than that in urban districts in the south, ${ }^{5}$ and the gradient of decreasing mortality from urban to rural areas may not persist for the remoter rural areas. ${ }^{6}$ Of the few datasets on morbidity that permit comparisons between urban and rural districts, most, such as the national morbidity study, ${ }^{7}$ point to better health in rural areas. But because such studies are rarely designed specifically for urban-rural comparison only a broad analysis is possible. However, a study in East Anglia which was designed to make this comparison used questions on self perceived illness similar to those in the general household survey and found higher prevalences of illness in rural areas. ${ }^{8}$ More recently, reanalysis of a large study of health and deprivation in the Northern region of England showed similar health patterns for matched urban and rural wards at the extremes of the socioeconomic range ${ }^{9}$ but, in contrast with Bentham's mortality study, ${ }^{6}$ a distinct health advantage for the remoter parts of the region over wards in the conurbations.

The information needed to make definitive statements on rural-urban patterns of disease is not available. Although most evidence points to greater morbidity in urban than rural areas, there is little to indicate whether this pattern holds for all rural populations in all degrees of rurality. More focused research is needed to assess how health need varies between rural and urban areas, especially for the most geographically isolated populations.

As provision of services becomes increasingly centralised ${ }^{10}$ isolated rural populations may have even less access to health care. Distance from a health facility is inversely associated with its use ${ }^{11}{ }^{12}$ : what is unclear is how much decrease in the use of health care represents unmet need. Within rural populations access may not be universally difficult and some 